\title{
RAMADAN FASTING AND MEDICAL SCIENCE
}

Though the Muslims all over the world are fasting for one lunar month each year from the 7th century, its effects on human, health were not studied till recently.

During 1958-63. the effect of Ramadan fasting was studied in different phases in Bangladesh (the then East Pakistan), From these studies it was clear that Ramadan fasting had no harmful effect on healthy adults on whom this fasting for one month is Significant findings :

1. Body weight : Ramadan fasting causes slow loss of body weight in $80 \%$ subjects; $8.0 \%$ showed no change of weight and about $12 \%$ showed some small increase in body
weight. ${ }^{2}$

Due to such painless slow weight loss, it has been suggested that Ramadan type of fasting for a period may be the better way of loosing weight by the obese people than by modern methods of dieting and the use of de-apetising drugs. ${ }^{3}$

2. Gastric juice analysis :

One month fasting caused change of hyper acidity and hypoacidity towards normal acidity in $80 \%$ subjects.

So, there is no connection of Ramadan fasting with peptic ulcer. If one suffers from active peptic ulcer one is not to keep fast, as illnes offers exemption from compulsory
fasting.

3. All the other physical and biochemical tests showed no harmful effects.

4. Effect on Pregnancy :

In a normal pregnancy (without any complication) fasting has no ill effect. In pregnancy BMR is normally increased and a normal rise of BMR was noted in a

5. Animal experiment showed no ill effect on animal health including the liver function tests.

Thus it was concluded that Ramadan Fasting had no ill effect on healthy subjects.

1. Muazzam, M.G.(1985) : Medical Research and Al-Qur'an (Alcoholism, Gambling and Fasting.

2. Muazzam, M. G and All, M.N (1967) : Effects of Ramadan Fasting on Body Weight, The Medicus. Karachi, $34: 134$

3. No. 1, P. 69

4. Muazzam. M. G. and Khaleque, KA (1959) : Effects of Fasting in Ramadan, J. Trop. Med. \& Hyg. 